\title{
Monitoring of Physical Activity of Soldiers of the Army of the Czech Republic during an Ordinary Week and During Continuous Field Training
}

Jan Zemánek, Miroslava Přidalová*

Palacký University Olomouc, Faculty of Physical Culture Czech Republic

DOI: $10.36348 /$ jaspe.2019.v02i10.002

| Received: 14.12.2019| Accepted: 21.12.2019| Published: 25.12.2019

*Corresponding author: Miroslava Přidalová

\section{Abstract}

\begin{abstract}
Aim: This research is aimed at the comparison of the amount of weekly physical activity of professional soldiers of the Army of the Czech Republic (soldiers of the $7^{\text {th }}$ mechanized brigade) during an ordinary week spent in the garrison and during a week of continuous field training. Methodology: The observed group was made up of 48 professional soldier volunteers in the age range of $30.12 \pm 4.84$ years. The measurement has been performed continuously during the time span of one week. Physical activity has been measured with the utilization of the ActiGraph GT1M accelerometers supplemented with the use of a weekly physical activity protocol. Results: Based on the results it is possible to infer that no difference has been found between the amount of weekly physical activity of the soldiers during a week spent in garrison and during a week of continuous field training in a military training area. The level of physical activity has been sufficient during both of the weeks. The average active energy expenditure has been $18.27 \mathrm{kcal}$ higher during the week of continuous field training. The average active power has been $5.06 \mathrm{kcal} / \mathrm{hour}$ higher during the ordinary week spent in garrison. Conclusion: Based on the values of average daily step count during an ordinary week in the garrison and during a week of continuous field training the soldiers' activity can be categorized as regular medium intensity movement without competitive sport activity (Máček et al., 2010) and meets the healthy recommended value of number of steps per day (Aoyagi \& Shephard, 2009).
\end{abstract}

Keywords: ActiGraph, motion, physical activity, BMI, monitoring.

Copyright @ 2019: This is an open-access article distributed under the terms of the Creative Commons Attribution license which permits unrestricted use, distribution, and reproduction in any medium for non-commercial use (NonCommercial, or CC-BY-NC) provided the original author and source are credited.

\section{INTRODUCTION}

Physical fitness is a basic obligation of every professional soldier [1]. Its development is ensured by the conduct of mandatory physical training during working hours. It is a controlled physical training conducted at designated times in designated facilities. The aim is to ensure the physical preparedness of the soldiers for the effective performance of their duties as determined by their job assignments [2] via a pedagogically controlled process. The amount of time dedicated weekly to physical training is given by the job assignment of the individual soldier. For example: 6 hours a week for pilots, 4 hours a week for members of combat units and 2 hours a week for logisticians [3].

The main task of a professional soldier during peace-time is to prepare for the defence of the Czech Republic, to improve his physical fitness, to improve his expert capabilities and to provide maintenance for his weapon and other materiel that he is responsible for.
This is also part of the Oath of the Soldier oh the Army of the Czech Republic. Czech soldiers have a fixed number of working hours per week, namely 40 hours a week, from Monday to Friday. The aims of expert training and education cannot be accomplished during an ordinary week in garrison. For this reason, most of the training is conducted in the form of continuous field training in military training areas. The field training is conducted in accordance with laws and regulations [1, $4]$, is not restricted by a number of training hours and is conducted continuously for a time span up to multiple weeks.

\section{METHODOLOGY}

The observed set was made up of professional soldier volunteers, members of the 73th tank battalion, 7th mechanized brigade. Measurement of weekly physical activity was based on voluntariness and has been conducted with consent of the participants. The measurement has been conducted during an ordinary 
week (in April) spent in the garrison and a week (in May) of field training, from Monday to Sunday in both cases. In both cases the monitored group was comprised by the same 48 individuals in the age range of $30.12 \pm$ 4.84 years without differentiating their level of physical fitness. During the week in garrison the weather conditions reached from sunny to partly cloudy with daily temperatures in the range of 11-16 degree of Celsius. The week of field training had mostly the same weather conditions with a range of daily temperatures 22-28 degree of Celsius. Somatic parameters of the monitored group are listed in Table 1 .

Table-1: The somatic description of the monitored group

\begin{tabular}{|l|l|l|l|l|}
\hline Parameter & M & SD & Min & Max \\
\hline Weight $[\mathrm{kg}]$ & 80.4 & 8.5 & 66.4 & 110.0 \\
\hline Height $[\mathrm{cm}]$ & 178.3 & 6.9 & 161.0 & 193.0 \\
\hline Age $[$ years] & 30.12 & 4.84 & 22.3 & 42.5 \\
\hline BMI $\left[\mathrm{kg} / \mathrm{m}^{2}\right]$ & 25.5 & 3.1 & 19.4 & 32.1 \\
\hline
\end{tabular}

Individuals with higher BMI values have a higher risk of formation of arteriosclerotic plates which clog arteries resulting in higher risk of cerebrovascular illnesses like strokes [5]. Scientific findings also show that more than $60 \%$ of all diseases are caused by an unhealthy lifestyle [6]. An average BMI value of BMI $>24.9 \mathrm{~kg} / \mathrm{m} 2$ corresponds to the overweight category according to Vítek [7], but for $80 \%$ of the group, who had a BMI value greater than $24.9 \mathrm{~kg} / \mathrm{m} 2$, this was caused by a higher ratio of muscle mass resulting in a higher body weight and thus in a higher BMI value. None of the group had a BMI value smaller than 18.5 $\mathrm{kg} / \mathrm{m} 2$, which would correspond to malnutrition [7].

The daily working-hours activity of the soldiers is determined by a 14-day activity schedule, which is produced by every unit commander based on his quarterly plan with regard to mandatory tasks given by his superior. This schedule is then approved by the battalion commander. During an ordinary week in the garrison every day usually starts with physical training, individual or controlled. After that the soldiers conduct military skills training (marching practice, regulations, shooting practice) and expert skills training (tactical training, CBRN training, medical training, topography, reconnaissance training,) according to their assigned field of expertise [8].

The aims of expert training and education cannot be accomplished during an ordinary week in garrison. For this reason, most of the training is conducted in the form of continuous field training in military training areas. The field training is conducted in accordance with laws and regulations [1,4], is not restricted by a number of training hours and is conducted continuously for a time span up to multiple weeks. Usually it consists of theoretical studies in classrooms, practical training in training areas, preparation of military equipment for training, transportation to the training areas and back, maintenance of equipment after the training, preparation for the training goals of the next day, individual studies, evaluation activities, resting time and other training and educational activities [9]. Extend of the training and its time duration depends on the level of preparedness and cooperation within the unit. Continuous military training is a continuous succession of training activities being conducted for time of at least 48 hours. During continuous military training the regulations regarding standard working hours, overtime and resting periods are not valid. Table 2 provides an example of 1 day on the weekly schedule of the training week.

Table-2: The sample of 1 day on the weekly schedule of the training week

\begin{tabular}{|c|l|}
\hline Time & \multicolumn{1}{c|}{ Activity } \\
\hline $06,00-06,30$ & \multicolumn{1}{c|}{ Reveille and morning hygiene } \\
\hline $06,30-07,00$ & \multicolumn{1}{c|}{ Meal } \\
\hline $07,00-13,00$ & $\begin{array}{c}\text { Patrolling - mobile patrol }-1^{\text {st }} \text { Platoon } \\
\text { Combat Shooting }-2^{\text {nd }} \text { Platoon }\end{array}$ \\
\hline $13,00-13,30$ & Meal \\
\hline $13,30-19,00$ & $\begin{array}{l}\text { Reconnaissance operations }-1^{\text {st }} \text { Platoon } \\
\text { Reconnaissance operations }-2^{\text {nd }} \text { Platoon }\end{array}$ \\
\hline $19,00-19,30$ & Meal \\
\hline $19,30-22,00$ & Preparation for next day \\
\hline $22,00-06,00$ & $\begin{array}{l}\text { Guarding }-2^{\text {nd }} \text { Platoon } \\
\text { The night mode at the base }-1^{\text {st }} \text { Platoon }\end{array}$ \\
\hline
\end{tabular}

Monitoring of physical activity has been conducted using the uniaxial accelerometer ActiGraph GT1M, which has provided continuous week-long monitoring of physical activity. The accelerometer ActiGraph GT1M measures the frequency, time and intensity of motion and provides an objective monitoring of the physical activity of the volunteers without age restriction. Based on the time the device has been worn and the measured physical activity it is possible to calculate also the physical inactivity of the volunteers, which represents a state of the organism with minimal body movement with energy requirements approximately equal to those of basal metabolism. We get the average active energy expenditure performance 
as the ration of the active energy expenditure and the time during which the accelerometer has been measuring the motion activity. Despite its simple construction, the accelerometer is considered a valid and dependable device for motion activity monitoring, particularly during multiple day or weekly-long use [10-12]. It has no negative effects on the wearer's health and does not produce any kind of EM radiation [13]. The device has always been worn during the whole day, with the exception of showering, bathing and swimming since it is not waterproof. The ActiGraph GT1M is storing average data over minute long intervals with the possibility to ascertain how many minutes have been spent with light, average or intensive physical activity during days and weeks [13].

Uniaxial accelerometers like the ActiGraph provide acceleration measurement only in the vertical plane resulting in a possible lower validity of the measurement during higher velocities of running locomotion in the sense of underestimating the energetic expenditure [14].

Accelerometer ActiGraph GT1M is shown in Figure 1. Figure 2 shows the correct way of wearing the device.

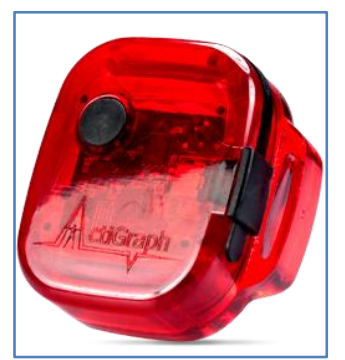

Fig-1: ActiGraph GT1M accelerometer (Mitáš et al., 2007)

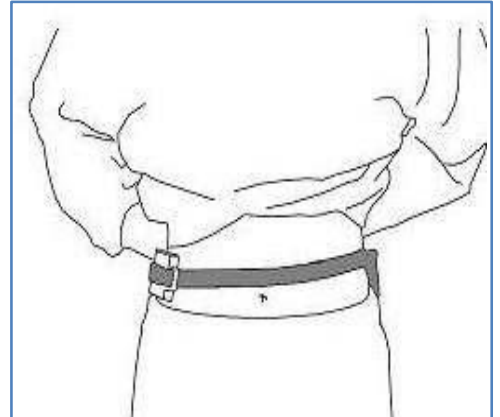

Fig.-2: Correct wearing of the ActiGraph GT1M (Mitáš et al., 2007)

The measured data has been processed using the ActiPA2006 software developed for research purposes of the Centre of Kinantropology Research of the Faculty of Physical Culture, Palacký University, Olomouc [15]. All statistical calculations have been made with STATISTICA 8.0. The descriptive characteristics have been expressed as medians, arithmetic averages, interquartile ranges and maximal and minimal values.

The t-test and Kruskal-Wallis test have been used for inter-group variable comparison. Statistical significance has been determined at a level of $\mathrm{p}<0.05$.

\section{RESULTS}

The overall daily average time spent wearing the ActiGraph GT1M device was 13.55 hours during the ordinary week (13hours 33 minutes) and 14.66 hours (14 hours 39 minutes) during the week of continuous field training. Table 3 shows the measured characteristics during these weeks.

Table-3: Characteristics measured during an ordinary week spent in the garrison and during a week of continuous field training

\begin{tabular}{|c|c|c|c|c|c|c|}
\hline Parameter & Week & $\mathbf{M}$ & $\mathbf{M i n}$ & $\mathbf{M a x}$ & $\mathbf{R}_{\mathbf{Q}}$ & $\mathbf{S D}$ \\
\hline PA & Ordinary & 7.66 & 3.88 & 11.71 & 6.35 & 1.64 \\
\hline & Training & 8.53 & 6.48 & 10.78 & 7.80 & 1.15 \\
\hline PI & Ordinary & 5.89 & 2.77 & 10.28 & 4.70 & 1.72 \\
\hline & Training & 6.11 & 3.50 & 11.15 & 5.24 & 1.48 \\
\hline IPA $>6$ & Ordinary & 8.48 & 0.14 & 41.42 & 1.40 & 9.33 \\
\hline & Training & 6.49 & 0.00 & 55.71 & 0.85 & 10.60 \\
\hline IPA3-6 & Ordinary & 34.60 & 5.57 & 62.57 & 22.65 & 14.72 \\
\hline & Training & 27.73 & 5.43 & 66.86 & 18.29 & 13.74 \\
\hline IPA<3 & Ordinary & 416.62 & 213.43 & 655.71 & 345.07 & 90.59 \\
\hline & Training & 477.31 & 358.57 & 636.14 & 440.85 & 67.49 \\
\hline AEE & Ordinary & 622.02 & 191.57 & 1504.57 & 415.96 & 263.97 \\
\hline & Training & 640.29 & 276.43 & 1552.29 & 499.57 & 231.99 \\
\hline AP & Ordinary & 49.05 & 17.13 & 195.16 & 35.68 & 27.74 \\
\hline & Training & 43.99 & 22.32 & 85.91 & 35.60 & 13.71 \\
\hline
\end{tabular}

Notes:

$\begin{array}{lll}\text { PA } & \text { average physical activity } & \text { [hod] } \\ \text { PI } & \text { average physical inactivity } & \text { [hod] } \\ \text { IPA }>6 & \text { average intensity of PA }>6 \text { METs } & \text { [min] }\end{array}$


IPA3-6

IPA $<3$

AEE

AP average intensity of PA 3-6 METs [min] average intensity of PA <3 METs [min] average active energy expenditure [kcal] average active power

[kcal/hod]

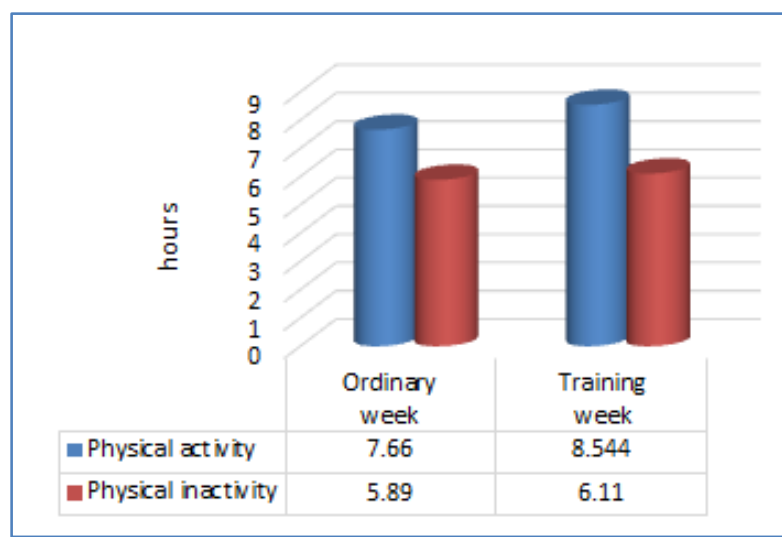

Fig-3: Average physical activity and inactivity during an ordinary week and a week of continuous field training

The graph in Figure 3 shows the average values of physical activity and inactivity during an ordinary week and a week of continuous field training. The average physical activity and inactivity in this graph have been higher during the week of field training. This difference has been statistically significant only in the case of average daily physical activity $(\mathrm{p}=0.005)$.

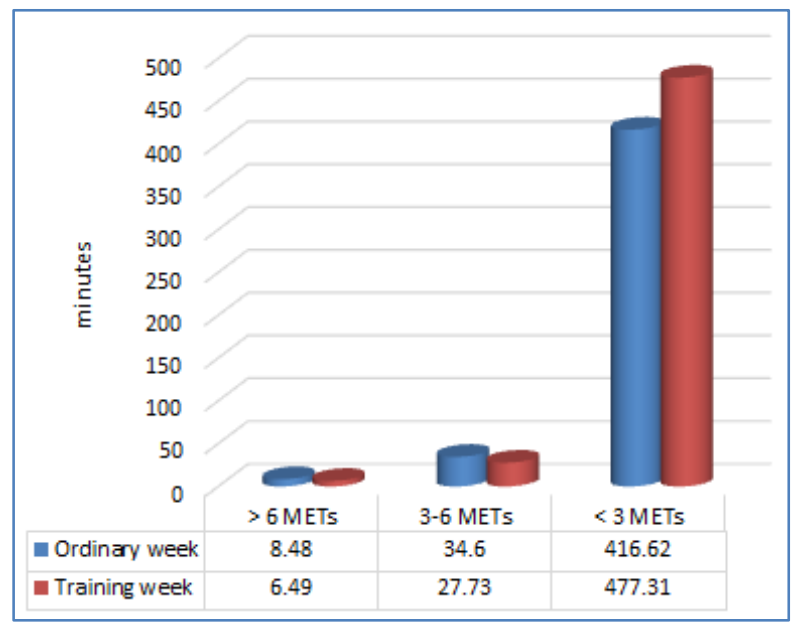

Fig-4: Average intensity of physical activity during an ordinary week and a week of continuous field training

The graph in Figure 4 shows the comparison of average intensity of physical activity of the soldiers during an ordinary week and a week of continuous field training. The average intensity of physical activity is separated into categories according to Frömel, Novosad \& Svozil [16]: low intensity (<3 METs; $<4 \mathrm{kcal} / \mathrm{min}$; walking), medium intensity (3-6 METs; 4-7 kcal/min, bicycle riding with velocities of $10-15 \mathrm{~km} / \mathrm{h}$ ) and high intensity (> $6 \mathrm{METs}$; $>7 \mathrm{kcal} / \mathrm{min}$, bicycle riding with velocities over $15 \mathrm{~km} / \mathrm{h}$ ).

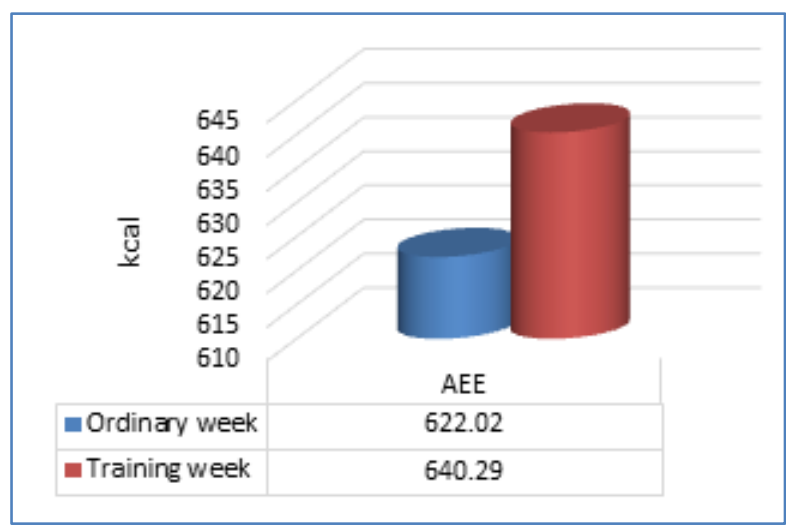

Fig-5: Average active energy expenditure [kcal] during an ordinary week and a week of continuous field training

The average active energy expenditure [kcal] shown in the graph in Figure 5 has been higher during the week of field training with a difference of 18.27 $\mathrm{kcal}$, the difference not being statistically significant $(\mathrm{p}=0.929)$.

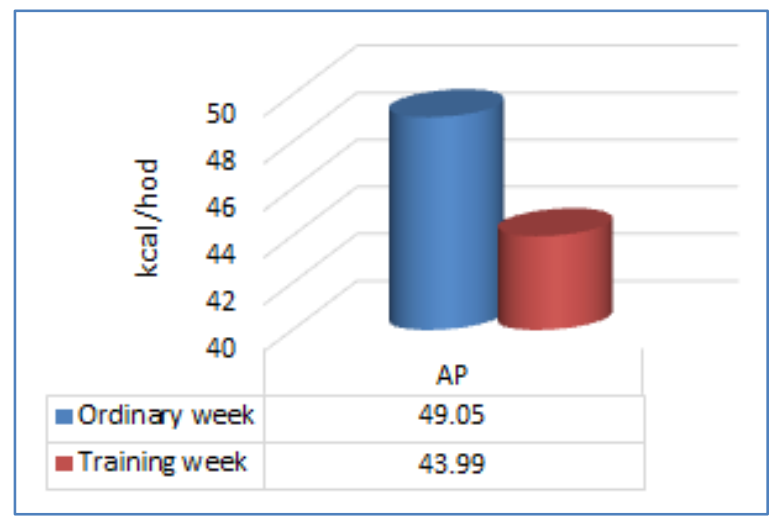

Fig-6: Average active power [kcal/hour] during an ordinary week and a week of continuous field training

The average active power [kcal/hour], shown in the graph in Figure 6, was higher during the ordinary week by a difference of $5.06 \mathrm{kcal} /$ hour, which is not statistically significant $(\mathrm{p}=0.449)$.

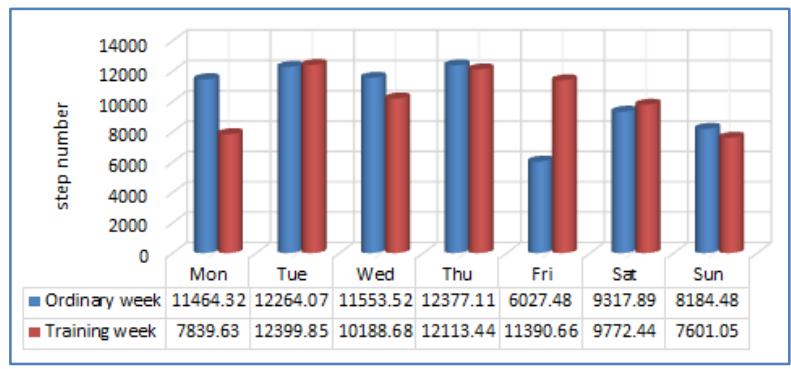

Fig-7: Comparison of average daily step count on days of the week during an ordinary week and a week of continuous field training 
It is apparent from Figure 7 that the minimal daily step count was achieved on Friday during the ordinary week. During this day the measured physical activity during working hours is higher than during offduty hours. The possible reason for this is that the working hours are shorter on Friday than on the other week-days.

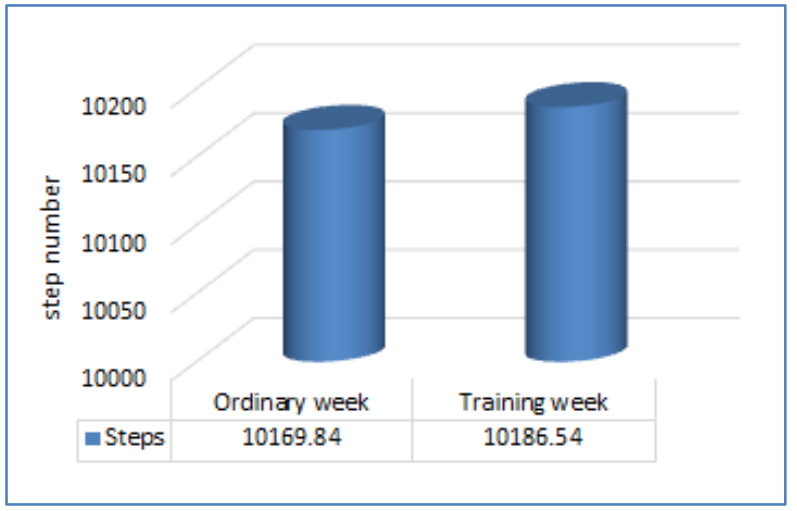

Fig-8: Average step count - ordinary week vs. a week of continuous field training

The graph in Figure 8 shows the comparison of the average step count during an ordinary week and a week of continuous training. The measured values are very similar; the step count during a training week is only 16.7 steps higher $(0.164 \%)$.

\section{DISCUSSION}

The average daily physical activity of the soldiers during a continuous field training week (8.54 hours) has been 52 minutes higher, which is a statistically significant difference $(p=0.005)$. The average physical inactivity during the training week (13 minutes) has been higher as well. This is caused by the higher amount of time the device has been worn during the days of the training (higher by 66 minutes/day).

Overall energy expenditure values are composed of the sum of the active energy expenditure and of the basal metabolism. The average active energy expenditure [kcal] during the training week has been higher by a difference of $18.27 \mathrm{kcal}$. The energy used for physical labour is expressed by a characteristic related to the active energy expenditure. The average active power [kcal/hour] during an ordinary working day was higher by a difference of $5.06 \mathrm{kcal} / \mathrm{hour}$. The average daily physical activity of the soldiers during the week-days of the training week was higher by a difference of 84 minutes, which is a statistically significant difference $(\mathrm{p}=0.000)$. Their physical inactivity during this period has been higher as well, by a difference of 32 minutes. The average daily time during which the device has been worn on these days has been higher by 116 minutes. The average active energy expenditure [kcal] was higher during these days by a difference of $0.97 \mathrm{kcal}$. The average active energy power [kcal/hour] was higher during the ordinary week in the garrison by a difference of $9.45 \mathrm{kcal} /$ hour.
The average daily physical activity during the days of the weekend of the ordinary week was higher by 28 minutes (for each day of the weekend). The average daily inactivity was also higher, by a difference of 35 minutes (for each day of the weekend). The average daily time during which the monitoring device has been worn during the weekend was 63 minutes higher during the ordinary week. During the training week the average active energy expenditure [kcal] was $61.52 \mathrm{kcal}$ higher and the average active power [kcal/hour] was higher by $5.93 \mathrm{kcal} /$ hour.

Uniaxial accelerometers provide acceleration measurement only in one direction, usually the vertical direction. The principle of using accelerometers for approximating physical activity is based on the relationship of acceleration being directly proportionate to muscle work and thus related to energy expenditure [17].

The average daily step count was $10,169.84$ during the ordinary week and 10,186.54 during the training week. This can be compared to German soldiers with an average daily step count of 12,984 [18] or with US soldiers with a count of 10,448 [19]. Both measured step count values can be categorized as "regular medium intensity movement without competitive sport activity", since they fit into the step count span of 10,000-12,499 per day [20, 21]. Both meet the health recommendation for daily step count according to Aoyagi \& Shephard [22] and Máček et al. [21].

\section{CONCLUSION}

There is no significant difference between the physical activity produced during an ordinary week in the garrison and a week of continuous field training. There is also no significant difference between the physical activity produced during the separate weekdays of an ordinary week and the days of continuous training and the same is true for the weekends.

\section{ACKNOWLEDGMENTS}

Thanks to doc. Mgr. Josef Mitáš, Ph.D. for providing data processing assistance and all people who were a part of the research. The research was supported by the research grant from the GAČR 15-13980S.

\section{REFERENCES}

1. Law no. 221/1999 Collection.

2. Ministry of Defence of the Czech Republic. (2011). Decree of the Ministry of Defence No. 12/2011. Prague.

3. Ministry of Defence of the Czech Republic. (2005). Prog-1-3. (Unit preparation program). Vyškov.

4. Hamar, D., \& Lipková, J. (2001). Physiology of physical exercises. Bratislava: Polygraphic center UK.

5. Svačina, S., \& Bretšnajdrová, A. (2008). How about obesity and its complications. Prague: Grada 
Publishing.

6. For̆t, P. (2005). Nutrition for perfect fitness and health. Prague: Grada.

7. Vítek, L. (2008). How to Affect Overweight and Obesity. Havlíčkův Brod: Grada Publishing.

8. Ministry of Defence of the Czech Republic. (2004). Prog-1-2. (Unit preparation program). Vyškov.

9. Vev-VA Vyškov. (2004). Recruitment Training Regulations. Vyškov: Military Academy.

10. Aadland, E., \& Ylvisåker, E. (2015). Reliability of the Actigraph GT3X+ Accelerometer in Adults under Free-Living Conditions. PLoS ONE, 10(8), e0134606.

11. Abel, M., G., Hannon, J., C., Sell, K., Lilie, T., Conlin, G., \& Anderson, D. (2008). Validation of the Kenz Lifecorder EX and ActiGraph GT1M accelerometers for walking and running in adults. Applied Nutrition, Physiology and Metabolism, 6, 1155-1164.

12. Rothney, M., P., Schaefer, E., V., Neumann, M., M., Choi, L., \& Chen, K., Y. (2008). Validity of Physical Activity Intensity Predictions by ActiGraph, Actical, and RT3 Accelerometers. Obesity (Silver Spring), 16(8), 1946-1952.

13. Mitáš, J., Sigmund, E., Frömel, K., Pelclová, J., \& Chmelík, F. (2007). Data processing and a feedback from the monitoring of physical activity using accelerometer Actigraph in the software ACTIPA2006. Czech kinanthropology, 11(4), 4048.

14. Brage, S., Wedderkoop, N., Franks, P., W., Andersen, L., B., \& Froberg, K. (2003). Reexamination of validity and reliability of the
CSA monitor in walking and running. Medicine and Science in Sports and Exercise, 35(8), 14471454.

15. Chytil, J. (2006). Software ActiPA2006 [Computer Software]. Olomouc: SoftWare Center.

16. Frömel, K., Novosad, J., \& Svozil, Z. (1999). Physical activity and sports interests of the youth. Olomouc: Palacký University.

17. Montoye, H. J., Kemper, H. C. G., Saris, W. H. M., \& Washburn, R. A. (1996). Measuring physical activity and energy expenditure. Human Kinetics, 72-79.

18. Schulze, C., Lindner, T., Goethel, P., Müller, M., Kundt, G., Stoll, R., \& Bader, R. (2015). Evaluation of the physical activity of German soldiers depending on rank, term of enlistment, and task area. Military Medicine, 180(5), 518-23.

19. Anders, A., Rune, H., Ingar, M., H., \& Sigmund, A., A. (2016). Objectively Measured Physical Activity in Home Guard Soldiers During Military Service and Civilian Life. Military Medicine, 181(7), 693-700.

20. Tudor-Locke, C., \& Bassett, D., R. (2004). How many steps/days are enough: preliminary pedometer indices for public health? Sports Medicine, 34, 1-8.

21. Máček, M., Máčková, J., \& Smolíková, L. (2010). Number of steps as a fitness indicator. Medicina Sportiva Bohemica et Slovaca, 19, 115-121.

22. Aoyagi, Y., \& Shephard, R., J. (2009). Steps per day: The road to senior health? Sports Medicine, 39, 423-438. 